\title{
Scepticism and Perceptual Justification ${ }^{1}$
}

\section{MATTHIAS STEUP}

\section{Three Responses to Scepticism}

The sixteen essays in this collection are clustered around issues that arise when we engage with the following two questions: 1. Under which conditions are perceptual experiences a source of epistemic justification? 2. Are perceptual experiences a sound basis for rejecting sceptical hypotheses? Crispin Wright has championed an important way of answering them: welfare epistemology. In “On Epistemic Entitlement (II): Welfare State Epistemology," Wright offers refinements of an earlier statement of his view ${ }^{3}$ and responds to criticisms and objections Aidan McGlynn and Duncan Pritchard advance in their respective contributions. In this review, I will focus on these three papers, as well as on Jonathan Vogel's essay on the problem of misleading evidence.

Wright distinguishes between two types of evaluative status: warrant and justification. Whereas justification for believing $p$ is always truth-connected and thus evidential, warrant to believe $p$ need not include evidence in support of $p$. It may result from the practical benefits that accrue to believing $p$. Instead of using the term 'warrant', I will use the expression 'having justification for believing $p$ ' to refer to $p$ 's having a generically positive evaluative status. To bring the intended contrast into sharp relief, I will use ' $\mathrm{J}_{\mathrm{E}}(p)$ ' to stand for 'having evidential justification for believing $p$,' and ' $\mathrm{J} \mathrm{P}(p)$ ' for having non-evidential, broadly practical justification for believing $p$. The kind of justification picked out by these locutions is propositional, and thus does not entail actual belief. ${ }^{4}$ With these stipulations in place, let us focus on a familiar sceptical argument, according to which our perceptual experiences do not provide $\mathrm{J}_{\mathrm{E}}$ for our beliefs about the world because there is no $\mathrm{J}_{\mathrm{E}}$ for believing that one is not a brain in a vat: ${ }^{5}$

\footnotetext{
1 Scepticism and Perceptual Justification. Edited by Dylan Dodd and Elia Zardini. Oxford: Oxford University Press, 2014. viii + 363 pp. Subsequently referenced as 'Dodd and Zardini'.

2 Dodd and Zardini, pp. 213-247.

3 Wright 2004.

${ }^{4}$ Propositional justification is to be contrasted with doxastic justification: a belief's having the property of being justified.

${ }^{5}$ A brain in a vat might be dead, and it might be alive and have a more or less horrific mental life. Here, 'BIV' will stand for 'I am a brain in a vat whose mental states duplicate the experience of a normal life'. 'Hands' stands for 'I have hands', and the expression $\mathrm{J}_{\mathrm{E}}$ (Hands) is to be read as 'I have evidential justification for believing that I have hands'.
} 


\section{The Brain in the Vat Argument}

$$
\begin{aligned}
& \sim \mathrm{J}_{\mathrm{E}}(\sim \mathrm{BIV}) \\
& \mathrm{J}_{\mathrm{E}}(\text { Hands }) \rightarrow \mathrm{J}_{\mathrm{E}}(\sim \mathrm{BIV})
\end{aligned}
$$

Therefore:

$$
\sim \mathrm{J}_{\mathrm{E}}(\text { Hands })
$$

The argument's second premise may be viewed as an abbreviated instance of the principle that $\mathrm{J}_{\mathrm{E}}$ is closed under known entailment. ${ }^{6}$ The thought is that, since one's having hands obviously entails one's not being a (handless) BIV, one cannot have $\mathrm{J}_{\mathrm{E}}$ for Hands without also having $\mathrm{J}_{\mathrm{E}}$ for $\sim \mathrm{BIV}$. The argument's first premise expresses the skeptic's trump card: one fails to have $\mathrm{J}_{\mathrm{E}}$ for $\sim \mathrm{BIV}$. Further below, I will discuss the reasoning in defense of this premise. For now, the point I'd like to make is that envatment (one's being a BIV) is just one among many skeptical hypotheses. Others are lying in one's bed dreaming, being deceived by an evil demon, and the world having popped into existence five minutes ago. If $\mathrm{J}_{\mathrm{E}}$ closure is true, it follows that we have $\mathrm{J}_{\mathrm{E}}$ for the ordinary things we believe about the external worldquotidian propositions henceforth—only if we also have justification for denying the aforementioned skeptical hypotheses. Wright calls such denials-e.g. that one is not envatted, or that the world is not five minutes old-cornerstone propositions. ${ }^{7}$ Cornerstones (for short) can be local and global. ${ }^{8}$ Here are two examples of local cornerstones: the red-looking table before me is not white with red lights shining at it, and the animal in the enclosure appearing to be a zebra is not a mule painted to look like a zebra. Denials of the familiar sceptical hypotheses are global cornerstones.

\footnotetext{
${ }^{6}$ With justification closure stated as an explicit premise, the BIV argument goes thus:

(1) $\sim \mathrm{J}_{\mathrm{E}}(\sim \mathrm{BIV})$

(2) $\mathrm{J}_{\mathrm{E}}\left(\right.$ Hands) $\& \mathrm{~J}_{\mathrm{E}}($ Hands $\left.\rightarrow \sim \mathrm{BIV})\right] \rightarrow \mathrm{J}_{\mathrm{E}}(\sim \mathrm{BIV})$

(3) $\mathrm{JE}_{\mathrm{E}}($ Hands $\rightarrow \sim \mathrm{BIV})$

Therefore:

(4) $\sim \mathrm{J}_{\mathrm{E}}(\sim$ Hands $)$

I take justification closure to be a thesis about how a subject's cognitive system is justificationally structured. Thus understood, the principle entails nothing about how, given $\mathrm{J}_{\mathrm{E}}$ (Hands) \& $\mathrm{J}_{\mathrm{E}}$ (Hands $\rightarrow \sim \mathrm{BIV}$ ), one's justification for $\sim \mathrm{BIV}$ comes about. The alternative reading is to take justification closure to be a principle about how justification is acquired via deduction. (For such an understanding of knowledge closure, see Hawthorne 2004.) It seems to me that, thus understood, it is not plausible that justification is closed under known entailment. A necessary truth is entailed by any proposition whatever. Surely, I cannot acquire justification for ' $2+2=4$ ' by virtue of being justified in believing (a) that the number of ants is greater than three, and (b) that that proposition entails ' $2+2=4$ '. See also note 24 .

${ }^{7}$ Dretske (2004) refers to such propositions as being 'heavyweight'. Wittgenstein calls them 'hinge propositions'; see section 11.1 of Wright's contribution in Todd and Zardini.

${ }^{8}$ Henceforth, the term 'cornerstone' will refer to global cornerstones unless indicated otherwise.
} 
The distinction between quotidian propositions and cornerstones allows us to see the BIV argument as an instance of a general argument in support of global scepticism about perceptual justification. It goes as follows: $\mathrm{J}_{\mathrm{E}}$ for quotidian propositions requires having $\mathrm{J}_{\mathrm{E}}$ for cornerstones. But there is no $\mathrm{J}_{\mathrm{E}}$ for cornerstones. Therefore, there is no $\mathrm{J}_{\mathrm{E}}$ for quotidian propositions. There are three principal ways of responding to this argument. They define the initial theoretical options.

Anti-scepticism

Closure denial

Scepticism
We have $\mathrm{J}_{\mathrm{E}}$ for quotidian propositions, and we have $\mathrm{J}_{\mathrm{E}}$ for

believing that the dreaded sceptical scenarios do not obtain.

$\mathrm{J}_{\mathrm{E}}$ closure is preserved.

We have $\mathrm{J}_{\mathrm{E}}$ for quotidian propositions although we never

have $\mathrm{J}_{\mathrm{E}}$ for cornerstones. $\mathrm{J}_{\mathrm{E}}$ is not closed under known

entailment.

We have $\mathrm{J}_{\mathrm{E}}$ neither for quotidian propositions nor for cornerstones. JE closure holds.

Closure denial is a concessive response, overlapping partially with the other two positions. Anti-scepticism and scepticism are in agreement about $\mathrm{J}_{\mathrm{E}}$ closure but otherwise concede nothing to each other.

\section{Dogmatic and Non-Dogmatic Anti-Scepticism}

Further theoretical options open up when we consider alternative ways in which the responses of anti-scepticism and closure denial can be pursued. The path of anti-scepticism can be followed in a dogmatic and a non-dogmatic way. According to dogmatic antiscepticism, perceptual justification, although defeasible, can be immediate. 'To say that a perceptual experience as of $p$ provides immediate justification for $p$ is to say that, if one has such an experience, one has a kind of justification for $p$ that does not require justification for any further propositions, such as propositions about the reliability of the experience, or about the non-obtaining of any sceptical scenarios in which $p$ is false. The anti-sceptical force of dogmatism is obvious. If dogmatism is true, then, for example, $\mathrm{J}_{\mathrm{E}}$ for $\sim \mathrm{BIV}$ is not needed for one's perceptual experiences to be a source of $\mathrm{J}_{\mathrm{E}}$. Your experiences of your hands

\footnotetext{
9 See Pryor 2000, 2004, and 2013. A similar position, labeled phenomenal conservatism, is defended in Huemer 2001. For a collection of critical essays on phenomenal conservatism and replies by Huemer, see Tucker 2014. There is significant overlap between the themes discussed in Todd and Zardini and Tucker 2014. For epistemologists working on the perceptual justification and scepticism, both volumes contain essential reading.
} 
provide $\mathrm{J}_{\mathrm{E}}$ for your belief that you have hands without any need for additional justification, such as $\mathrm{J}_{\mathrm{E}}$ for believing that you are not a BIV. Since hand possession obviously entails nonenvatment, recognition of this entailment enables your hand experiences to supply you with $\mathrm{J}_{\mathrm{E}}$ for believing that you are not a BIV. The upshot is that, according to dogmatic antiscepticism, G. E. Moore's notorious Hands Argument does not, as is frequently held, beg the question. Rather, it is a legitimate way of rejecting skeptical hypotheses that are inconsistent with hands possession. Let us consider the argument:

\section{The Hands Argument}

$$
\begin{aligned}
& \mathrm{J}_{\mathrm{E}}(\text { Hands }) \\
& \mathrm{J}_{\mathrm{E}}(\text { Hands } \rightarrow \sim \mathrm{BIV})
\end{aligned}
$$

Therefore:

$$
\mathrm{J}_{\mathrm{E}}(\sim \mathrm{BIV})
$$

Dogmatists claim that hand experiences give you, all by themselves, $\mathrm{J}_{\mathrm{E}}$ for believing that you have hands. You also have, unproblematically, $\mathrm{J}_{\mathrm{E}}$ for the entailment from hand possession to non-envatment. As a result, you acquire $\mathrm{J}_{\mathrm{E}}$ for $\sim \mathrm{BIV}$ that you did not possess previously. The justification you acquire in this way comes from two and only two sources: hands experiences and a priori recognition of the entailment from hands possession to nonenvatment. $^{10}$

Wright doesn't buy it. He thinks that hand experience by themselves cannot justify belief in hand possession. They can do so only if one already has justification for rejecting the envatment hypothesis and related sceptical threats. This position that has been labeled conservatism. ${ }^{11}$ Conservatives hold that defeasible justification cannot be immediate because it always comes in part from justification for rejecting local and global sceptical alternatives. Put differently, perceptual justification for quotidian propositions invariably flows in part from justification for cornerstones.

\footnotetext{
${ }^{10}$ Arguments of this type run into the problem of easy knowledge. See Cohen 2004. In a nutshell, if the Hands Argument is legitimate, it should also be legitimate to reason thus: Since this table looks red to me, I'm justified in believing it's red. Therefore, I'm justified in believing it's not white and illuminated by red light. In his 2004, Pryor recognizes the threat and bites the bullet. He claims that a table's looking red to one gives one some degree of justification for concluding it's not a white table with red lights shining at it. To account for the seeming badness of such reasoning, he grants that the reasoning in question, while justification conferring, is dialectically ineffective. It won't persuade a critic who challenges one with the white table/red light possibility. 11 As a label for the rejection of dogmatism, the term 'conservatism' was introduced by Pryor in his 2004 . Since Huemer's phonemenal conservatism (see his 2001) is a version of dogmatism, the choice of this term is somewhat unfortunate. In some literature, the term 'conservative' refers to a dogmatic position and in other literature, the term refers to the rejection of that position.
} 
Conservatism comes in two forms: evidential and non-evidential. According to the evidential kind, $\mathrm{J}_{\mathrm{E}}$ for quotidian propositions requires $\mathrm{J}_{\mathrm{E}}$ for cornerstones. According to the non-evidential kind, the one that Wright advocates, $\mathrm{J}_{\mathrm{E}}$ for quotidian propositions requires justification for cornerstones, but that justification need not and cannot be evidential. Similarly, anti-scepticism is either evidential or non-evidential. According to evidential antisceptism, we have $\mathrm{J}_{\mathrm{E}}$ for both quotidian propositions and cornerstones. According to nonevidential anti-scepticism, such as Wright's welfare epistemology, we have $\mathrm{J}_{\mathrm{E}}$ for quotidian propositions but not for cornerstones. Wright claims that the idea of there being $\mathrm{J}_{\mathrm{E}}$ for rejecting sceptical hypotheses is incoherent. ${ }^{12}$ At the same time, though, he holds that we have $\mathrm{J}_{\mathrm{p}}$ for cornerstones, a kind of default justification that is unearned yet epistemically significant.

\section{Closure Denial and Welfare Epistemology}

Next, let us consider the denial of justification closure. The case for it is based on two premises:

(i) In typical cases, we have $\mathrm{J}_{\mathrm{E}}$ for quotidian propositions.

(ii) $\mathrm{J}_{\mathrm{E}}$ for cornerstone propositions is not possible.

If (i) and (ii) are true, then we get cases in which we have $\mathrm{J}_{\mathrm{E}}$ for a particular quotidian proposition and lack $\mathrm{J}_{\mathrm{E}}$ for the relevant cornerstones. For example, if (i) and (ii) are true, then people with hands will (normally) be in this position: they have $\mathrm{J}_{\mathrm{E}}$ for believing they have hands, they lack $\mathrm{J}_{\mathrm{E}}$ for believing they are not envatted, while it is (or at least could be) obvious to them that hand possession entails non-envatment. So (i) and (ii) necessitate the outcome that $\mathrm{J}_{\mathrm{E}}$ is not closed under known entailment. The problem with this view is that it's committed to abominable conjunctions. ${ }^{13}$ Consider: I'm justified in believing that I have hands, but I'm not justified in believing that I'm not a (handless) BIV. It is difficult to see how it could be rational to assert the former while conceding the latter.

Wright's antidote to scepticism is to abandon $\mathrm{J}_{\mathrm{E}}$ closure while upholding an alternative closure principle. On his view, you have (assuming you have hands) Je for Hands, you do not have $\mathrm{J}_{\mathrm{E}}$ for $\sim \mathrm{BIV}$, while at the same time you know that hand possession entails nonenvatment. But from the fact you lack $\mathrm{J}_{\mathrm{E}}$ for nonenvatment, it doesn't follow that you have

${ }^{12}$ See section 11.8 in Wright's contribution to Todd and Zardini.

13 The term was coined by De Rose in his 1995. 
no justification at all for rejecting the envatment hypothesis. You do have justification. It is non-evidential, practical, and you have it by default. So Wright's position on closure is the following. On the one hand, he endorses a broad closure principle according to which $\mathrm{J}_{\mathrm{E}}$ for quotidian propositions is closed under known entailment at least inasmuch as $\mathrm{J}_{\mathrm{E}}$ for quotidian propositions necessarily comes together with $\mathrm{J}_{\mathrm{p}}$ for entailed cornerstones. On the other hand, since Wright endorses (ii) above, securing $\mathrm{J}_{\mathrm{E}}$ for quotidian propositions requires of him to reject $\mathrm{J}_{\mathrm{E}}$ closure. So, according to Wright: $\sim\left\{\left[\mathrm{J}_{\mathrm{E}}(\mathrm{p}) \& \mathrm{~J}_{\mathrm{E}}(\mathrm{p} \rightarrow \mathrm{q})\right] \rightarrow \mathrm{J}_{\mathrm{E}}(\mathrm{q})\right\} .{ }^{14}$

Welfare epistemology, then, is located within a somewhat complex web of theoretical options for the anti-skeptic. Its defining characteristics are the following:

(i) It is anti-sceptical: we have $\mathrm{J}_{\mathrm{E}}$ for quotidian propositions.

(ii) It affirms a version of justification closure: Whenever one knows a quotidian proposition $p$ to entail a cornerstone proposition $q$, then $\mathrm{J}_{\mathrm{E}}$ for $p$ entails $\mathrm{J}_{\mathrm{p}}$ for $q$, without, however, entailing $\mathrm{J}_{\mathrm{E}}$ for $q$.

(iii) It is conservative, i.e., opposed to dogmatism: perceptual justification for quotidian propositions cannot be immediate; it requires justification for cornerstone propositions.

(iv) It is non-evidential, i.e., opposed not only to dogmatism but also to nondogmatic evidential anti-scepticism: $J_{\mathrm{E}}$ for cornerstone propositions is unavailable.

With features (i) - (iv) in place, the foundation is laid for the welfare aspect of Wright's epistemology:

(v) Perceptual experiences are a source of justification because we have a nonevidential, unearned, default-type of justification for rejecting sceptical scenarios: Jp for the cornerstone propositions on which the evidential power of perception rests.

Next, I will focus on feature (iv).

\footnotetext{
14 See Duncan Prichard's contribution to Todd and Zardini, pp. section 10.1.
} 


\section{Is There $J_{E}$ for Cornerstones?}

Wright rejects the Hand Argument as epistemological alchemy because it moves against the direction of the evidential flow. ${ }^{15}$ Hand experiences are $\mathrm{J}_{\mathrm{E}}$ for Hands only if one already has justification for $\sim \mathrm{BIV}$. That is why hand experiences cannot provide $\mathrm{J}_{\mathrm{E}}$ flowing in the opposite direction, supplying $\mathrm{J}_{\mathrm{E}}$ for $\sim \mathrm{BIV}$. Now, it is possible to agree with Wright on rejecting the Hands Argument as alchemy while rejecting his claim that $\mathrm{J}_{\mathrm{E}}$ for cornerstones is impossible. This is the position of non-dogmatic evidential anti-scepticism. To investigate the prospects for a non-dogmatic yet evidential alternative to the Hands Argument, I next turn to Pritchard's essay "Entitlement and the Groundlessness of Our Believing." "There, Prichard makes an important point about the relationship between perceptual justification for believing "There is a zebra in the pen" (Zebra) and the local cornerstone "The animal in the pen is not a cleverly disguised mule" ( $\sim \mathrm{CDM})$. There is some temptation to view the zebra case as a challenge to $\mathrm{J}_{\mathrm{E}}$ closure. Looking at a zebra in a zoo, you have $\mathrm{J}_{\mathrm{E}}$ for Zebra, you unproblematically know Zebra $\rightarrow \sim \mathrm{CDM}$, but you don't have $\mathrm{J}_{\mathrm{E}}$ for $\sim \mathrm{CDM}$. Pritchard argues that the latter claim is false. You do have $\mathrm{J}_{\mathrm{E}}$ for $\sim \mathrm{CDM}$, namely a rich body of evidence having to do with the behavior of zoos and the staggering improbability of the deception in question. So $\mathrm{J}_{\mathrm{E}}$ closure holds. ${ }^{17}$ Analogous points can be made for similar cases, for example the red looking table and the possibility of its being a white table in a red light environment. ${ }^{18}$ So $\mathrm{J}_{\mathrm{E}}$ for local cornerstones is easily available. However, Prichard is adamant that, when it comes to global cornerstones, $\mathrm{J}_{\mathrm{E}}$ cannot materialize in such fashion.

Suppose, when you are at the zoo, a distinguished zoologist tells you that the animal in the enclosure is definitely not a mule. Prichard would say that her testimony gives you $\mathrm{J}_{\mathrm{E}}$ for $\sim$ CDM. Now suppose you ask a renowned neuroscientist at a prestigious university whether envatment is possible. She tells you that it is not. Keeping a separated brain alive and providing it with the sensory input needed for duplicating the experience of a normal life requires technology and know-how we don't have. So, according to the neuroscientist you

\footnotetext{
15 Referring to the Hands Argument as 'alchemy' was introduced in Davies 2004 in the context of arguing that, in this argument, justification is not transmitted from the premises to the conclusion.

16 Todd and Zardini, pp. 190-212.

17 Ibid, pp. $200 f$.

${ }^{18}$ In typical cases, to acquire $\mathrm{J}_{\mathrm{E}}$ for believing that the red looking table in front of one is not bathed in red light, all one has to do is look whether any red light sources are nearby.
} 
consulted, BIVs do not and cannot exist at the present time. ${ }^{19}$ Now we have what looks like a promising alternative to the Hands Argument: ${ }^{20}$

\section{The BIV Non-Existence Argument}

$$
\begin{aligned}
& \mathrm{J}_{\mathrm{E}}(\mathrm{BIV} \text { s don't exist.) } \\
& \mathrm{J}_{\mathrm{E}}(\mathrm{BIV} \text { s don't exist } \rightarrow \sim \mathrm{BIV})
\end{aligned}
$$

So:

$$
\mathrm{J}_{\mathrm{E}}(\sim \mathrm{BIV})
$$

Whereas the first premise of the Hands Argument is justified by hand experiences, what justifies this argument's first premise is a neuroscientist's testimony. ${ }^{21}$ Prichard wouldn't buy that the Non-Existence argument is better than the Hands Argument. He would argue that the BIV hypothesis calls the expert testimony into question, just as it calls hands experiences into question. ${ }^{22}$ But the CDM hypothesis does not call the zoologist's testimony into question. That is why the zoologist's testimony gives you $\mathrm{J}_{\mathrm{E}}$ for the local $\sim \mathrm{CDM}$ cornerstone, whereas the neurologist's testimony does not gives $\mathrm{J}_{\mathrm{E}}$ for the global $\sim \mathrm{BIV}$ cornerstone. Wright, too, would argue that the Non-Existence Argument fails. According to him, the neurologist's testimony cannot give you $\mathrm{J}_{\mathrm{E}}$ for $\sim$ BIV because, if the neurologist's testimony is to be a source of $\mathrm{J}_{\mathrm{E}}$ for you, you must, to begin with, have justification for rejecting the BIV hypothesis.

\section{Evidential Self-Defense}

Prichard and Wright assert what we might call cornerstone scepticism: $\mathrm{J}_{\mathrm{E}}$ for cornerstones is not possible. Here is another example illustrating this kind of scepticism. Suppose I'm part of a caravan crossing a desert. After a long period of extreme heat and thirst, I appear to be seeing a cluster of palm trees at the horizon. An oasis, I think. But I worry I might by hallucinating. Let's stipulate:

$$
H=\text { I'm hallucinating an oasis. }
$$

\footnotetext{
19 Again, 'BIV' refers to separated brains that are alive and have mental states duplicating the experience of a normal life. Thus, the imagined neuroscientist should not be misunderstood as claiming that dead brains in vats, or brains in vats alive for only a brief moment, do not exist.

20 There are, of course, many other arguments along these lines.

${ }^{21}$ More precisely, what justifies the first premise is a complex perceptual experience of a neuroscientist's telling one that BIVs don't exist. For ease of exposition, I will refer to the testimony itself as the source of justification for the first premise.

22 See Todd and Zardini, p. 201.
} 
Suppose further it so happens a distinguished neurologist is among the desert travelers. After examining me, she tells me that I'm not having any hallucinations. ${ }^{23}$ Now I reason:

(1) I have $\mathrm{J}_{\mathrm{E}}$ for $\sim H$ because a neuroscientist tells me I'm not hallucinating. $H$ does not call into question the neuroscientist's testimony. Prichard would therefore say that the neuroscientist's testimony gives me $\mathrm{J}_{\mathrm{E}}$ for the local cornerstone $\sim H$. However, there is another hallucination hypothesis that must be considered as well. Let's stipulate:

$H^{*}=$ I'm hallucinating a neuroscientist telling me I'm not hallucinating. How might I argue against $H^{*}$ ? One way of rejecting $H^{*}$ is to say the following:

(2) I have $\mathrm{J}_{\mathrm{E}}$ for $\sim H^{*}$ because a neuroscientist tells me I'm not hallucinating. Prichard and Wright would reject (2), just as they reject that a neuroscientist can give me $\mathrm{J}_{\mathrm{E}}$ for $\sim$ BIV. Arguably, the rejection of (2) is not a happy outcome. Let us see whether it can be avoided. Compare (2) with

(3) I have $\mathrm{J}_{\mathrm{E}}$ for $\sim H$ because I'm having an oasis-like visual experience. ${ }^{24}$ Though (3) is a clear case of begging the question, it is not obvious that (2) is. But if there is a difference between (2) and (3), what might it be?

It could be argued the difference has to do with the nature of evidence. Assume that a particular body of evidence, $E$, can be evidence for $p$ and evidence for $\sim(E \& \sim p)$. Let's say that, if $E$ is evidence for $p$ and evidence for $\sim(E \& \sim p)$, then $E$ instantiates the relation of evidential self-defense. Allowing for the possibility of evidential self-defense, we could say that the difference between (2) and (3) is as follows:

(4) The neuroscientist's telling me I'm not hallucinating is evidence for $\sim(\mathrm{I}$ am having an experience of a neurologist telling me I'm not hallucinating \& $\left.H^{*}\right)$. An oasis-like visual experience is not evidence for $\sim(I ' m$ having an oasis-like visual experience $\& H)$.

In short: in the case we are imagining, whereas the neuroscientist's testimony is evidence for believing that that testimony is not misleading, my oasis-like visual experience is not evidence that that experience is not misleading.

\footnotetext{
${ }^{23}$ Let's assume that, on the basis of a quick and reliable neuroscientific test, what the neuroscientist is telling is that I'm not hallucinating in any way.

24 This example serves to support the point I made in note 6: not any deduction is suitable for acquiring justification the conclusion. That I'm seeing an oasis entails that I'm not hallucinating an oasis. But I can't acquire justification for believing I'm not hallucinating an oasis by arguing: "I have a visual experience of an oasis. So I'm seeing an oasis. My seeing an oasis entails I'm not hallucinating an oasis. So I'm not hallucinating an oasis."
} 
If we wonder why (4) and (5) differ in this way, Wright's conservative rejection of the Hand Argument will be of service. For my hand experiences to be $\mathrm{J}_{\mathrm{E}}$ for hand possession, I must already have $\mathrm{J}_{\mathrm{E}}$ for $\sim \mathrm{BIV}$ (and for the denial of other sceptical hypotheses that duplicate the experience of hand possession). That's why hand experiences cannot be $\mathrm{J}_{\mathrm{E}}$ for $\sim$ BIV. Likewise, for my oasis-like visual experience to be $\mathrm{J}_{\mathrm{E}}$ for believing an oasis is nearby, I must already have $\mathrm{J}_{\mathrm{E}}$ for $\sim H$. That's why an oasis-like visual experience can’t be $\mathrm{J}_{\mathrm{E}}$ for $\sim H$. And likewise, for the neurologist's testimony that I'm not hallucinating, I must already have $\mathrm{J}_{\mathrm{E}}$ for $\sim H^{*}$. But here is the rub: the neuroscientist's testimony already is $\mathrm{J}_{\mathrm{E}}$ for $\sim H^{*}$. So the neuroscientist's testimony is $\mathrm{J}_{\mathrm{E}}$ for both $\sim \mathrm{H}$ and $\sim \mathrm{H}^{*}$, and thus is evidence for me to believe that it is not misleading evidence.

Let's apply this thought to the two anti-envatment arguments we considered in the previous section. Prichard and Wright would claim the Non-Existence Argument is no better than the Hands Argument; neither one is capable of generating $\mathrm{J}_{\mathrm{E}}$ for the $\sim \mathrm{BIV}$ cornerstone. In defense of the BIV Non-Existence Argument, it could be argued, however, that hands experiences and a neuroscientist's testimony that BIVs don't exist are different in a crucial respect. Hand experiences are $\mathrm{J}_{\mathrm{E}}$ for Hands only if one already has $\mathrm{J}_{\mathrm{E}}$ for $\sim \mathrm{BIV}$. Therefore, hand experiences are not $\mathrm{J}_{\mathrm{E}}$ for $\sim \mathrm{BIV}$. Likewise, scientific testimony that BIVs don't exist is evidence of BIV non-existence only if one already has $\mathrm{J}_{\mathrm{E}}$ for $\sim \mathrm{BIV}$. However, the scientific testimony that BIVs don't exist already is $\mathrm{J}_{\mathrm{E}}$ for $\sim \mathrm{BIV}$.

\section{Is Evidential Self-Defense Plausible?}

Is it plausible to think that there is such a thing as evidential self-defense? According to Jonathan Vogel, it is. In " $\mathrm{E} \& \neg \mathrm{H}$," he discusses what he calls the problem of misleading evidence. ${ }^{25}$ This is the problem of how one might justify that one's evidence $E$ for $p$ is not misleading, i.e., how one might justify $\sim(E \& \sim p)$. The answer he defends is that $E$ itself can justify $\sim(E \&$ $\sim p)$.

An obstacle blocking this answer is what's known as the entailment principle: if $p \rightarrow q$ then $\mathrm{J}_{\mathrm{E}}$ for accepting $q$ cannot provide $\mathrm{J}_{\mathrm{E}}$ for rejecting $p \cdot{ }^{26}$ If the entailment principle is true, evidential

\footnotetext{
25 Todd and Zardini, pp. 87-107.

26 The principle is typically expressed by saying that, if $p$ entails $q$, then $q$ cannot justify $\sim p$. But if propositions are abstract objects, I don't see how they can justify anything. As I see it, justification always comes from our cognitive relations to propositions. In their debate over the possibility of immediate justification, Comesana
} 
self- defense is not possible; if self-defense is possible, then the entailment principle is false. Here is why: the conjunction $E \& \sim p$ entails $E$. So, if the entailment principle is true, $E$ cannot be $\mathrm{J}_{\mathrm{E}}$ for $\sim(E \& \sim p)$. And if $E$ can be $\mathrm{J}_{\mathrm{E}}$ for $\sim(E \& \sim p)$, then the entailment principle is false. One way of providing support for evidential self-defense, then, is to attack the entailment principle. Vogel does just that. He thinks there are counterexample to it. Here is one of three cases he presents. Let the entailing proposition be

$$
p \quad=\quad \text { This winter will be the first not to be followed by spring, }
$$

and let the entailed proposition be

$$
q=\text { Winter has always been followed by spring. }
$$

Arguably, $\mathrm{J}_{\mathrm{E}}$ for $q$ is $\mathrm{J}_{\mathrm{E}}$ for $\sim p .^{27}$

Another way of supporting the possibility of self-defense is to find plausible instances of it. I myself think it is plausible to say that, when $E$ is a neuroscientist's testimony that I'm not hallucinating, her testimony is evidence for believing that $\sim(\mathrm{I}$ have the experience of a neuroscientist telling me I'm not hallucinating \& $\left.H^{*}\right)$. And it seems even more plausible to me that, when $E$ is the totality of my reasons for believing that Napoleon is dead, $E$ is evidence for believing that $\sim(\mathrm{I}$ have reasons to believe that Napoleon is dead \& I'm a BIV in Napoleon's envatment lab). ${ }^{28}$ And here is a third example. Consider a body of evidence, $E^{*}$, giving me $\mathrm{J}_{\mathrm{E}}$ for believing that the table before me is red (Red). $E^{*}$ consists of the visual experience of the table's looking red to me and further evidence that there are no nearby red lights, that I'm not wearing red-colored glasses, and that I haven't taken any drugs causing me to hallucinate red surfaces. I think it is plausible to claim that $E^{*}$ is evidence for $\sim\left(E^{*} \&\right.$ $\sim$ Red) although $\left(E^{*} \& \sim\right.$ Red $)$ entails $E^{*}$. Whereas Vogel's example provides indirect support for self-defense by directly attacking the entailment principle, these three example support self-defense directly, thereby indirectly providing reasons for rejecting the entailment principle.

A third way of supporting evidential self-defense focuses on the nature of deception. Successful deception entails providing the deceived subject with evidence against deception. Suppose someone wants to kill Jones and frame Smith for the murder. This involves, among

(2013) raises trouble for dogmatism by deploying the entailment principle, and Pryor (2013) defends dogmatism by rejecting that principle.

27 Todd and Zardini, p. 92. Vogel presents as well additional considerations counting against the entailment principle.

28 The sceptical hypothesis entertained here is that Napoléon Bonaparte is still alive in 2015 and running a secret envatment lab. 
other things, planting Smith's fingerprints on the murder weapon. It also involves fabricating a body of evidence that is both $\mathrm{J}_{\mathrm{E}}$ for believing Smith murdered Jones and $\mathrm{J}_{\mathrm{E}}$ for believing Smith is not being framed. Likewise, if a criminal scientist wants to envat you in such a way that your being a BIV is completely concealed from you, he must give you evidence for believing (among other things) that you have a body and evidence for believing that envatment is nothing to worry about. In other words, the criminal scientist must give you an evidential system providing you with $\mathrm{J}_{\mathrm{E}}$ for believing that your evidence for thinking you have a body is not misleading. The point is that a BIV's total evidence necessarily defends itself against the envatment hypothesis.

What position does dogmatism take regarding the plausibility of self-defense? Dogmatists must accept the possibility of evidential self-defense and reject the entailment principle. ${ }^{29}$ For example, let $E$ be my hand experiences. According to dogmatism, E gives me $\mathrm{J}_{\mathrm{E}}$ for $\sim \mathrm{BIV}$, and thus gives me $\mathrm{J}_{\mathrm{E}}$ for $\sim(\mathrm{E} \& \sim$ Hands $)$. There is, however, a gulf between the dogmatic and the non-dogmatic account of how evidential self-defense works. According to dogmatism, a neuroscientist's testimony that I'm not hallucinating is by itself evidence for $\sim H^{*}$, i.e., for believing that this experience is not misleading. According to the non-dogmatic alternative, her testimony is evidence for believing her testimony is not misleading only if that testimony is embedded in a large body of evidence confirming the testimony's reliability and confirming the reliability of that body of evidence itself. I perceive the scientist telling me I'm not hallucinating. This perceptual experience is a source of $\mathrm{J}_{\mathrm{E}}$ in part because I have perceptual evidence for considering perception to be reliable. Evidence for considering perception reliable also comes from memory. My memory's testimony is a source of $\mathrm{J}_{\mathrm{E}}$ because its own testimony confirms that it is reliable. What emerges is a large evidential structure in which perception is used to provide $\mathrm{J}_{\mathrm{E}}$ for the reliability of perception, and memory is used as a source of $\mathrm{J}_{\mathrm{E}}$ for the reliability of memory. So according to the conservative version of evidential anti-scepticism, the experience of a neuroscientist telling I'm not hallucinating self-defends against $\mathrm{H}^{*}$ by virtue of being integrated into a large body of evidence that certifies its own reliability. ${ }^{30}$

${ }^{29}$ See Comesaña (2013) and Pryor (2013).

${ }^{30} \mathrm{I}$ have defended a response to scepticism along these lines in Steup (2004), (2008), and (2013). 


\section{7. $J_{P}$ as a Foundation for $J_{E}$}

Suppose we accept the possibility of evidential self-defense. If we do, JE for cornerstones begins to materialize. That's one challenge for welfare epistemology. Another one arises within the project itself. Its central claim is that $\mathrm{J}_{\mathrm{p}}$ for the cornerstones makes it possible for perceptual experiences to give us $\mathrm{J}_{\mathrm{E}}$ for quotidian propositions. If that claim is right, then $\mathrm{J}_{\mathrm{P}}$ at the cornerstone foundation is somehow the catalyst for $\mathrm{J}_{\mathrm{E}}$ within the quotidian superstructure. Evidential juice flows from a non-evidential fruit. One might suspect that that is not possible. The juice coming from a non-evidential fruit will always lack the crucial ingredient: the property of generating likelihood of truth. Wright refers to this challenge as the leaching problem. The threat is that only $\mathrm{J}_{\mathrm{P}}$ is seeping up from the cornerstone foundation into the quotidian superstructure. $\mathrm{J}_{\mathrm{E}}$ never emerges. ${ }^{31}$ According to Prichard, this is indeed the core problem for welfare epistemology. He considers the problem fatal because, if one reflects on one's justification for the cornerstones and comes to see that one fails to have $\mathrm{J}_{\mathrm{E}}$ in support of them, then the rationally appropriate attitude regarding quotidian propositions must be that of agnosticism: one is no longer in a position to think that one's ordinary beliefs are likely true. ${ }^{32}$

In response, Wright attempts to soften up the distinction between pragmatic and evidential justification. ${ }^{33}$ He says: "An entitlement . . marks the presence of a pragmatic reason. But because the values to which it is in service are epistemic values-the maximizing of true and useful belief - it is also an epistemic reason." 34 This strategy conflicts with an essential plank of Wright's overall view: JE for cornerstone propositions is impossible. To the extent Wright attempts to evidentialize Jp, he chips away at that plank. Moreover, arguably the difference between evidential and practical justification is like that between odd and even numbers. It's necessarily one or the other. Evidential justification for $p$ makes it likely that $p$ is true. Practical justification does not—not even a little bit. One might suspect, therefore, that the strategy of softening up the $\mathrm{J}_{\mathrm{E}}-\mathrm{J}_{\mathrm{P}}$ difference is a dead end. On behalf of welfare epistemology, the reply to Prichard should be that, since dogmatism is unacceptable and $\mathrm{J}_{\mathrm{E}}$ for cornerstones impossible, we simply have to live with the outcome that $\mathrm{J}_{\mathrm{E}}$, the kind of

31 Todd and Zardini, p. 228.

32 Ibid, p. $197 f$.

33 Ibid, pp. 235-239.

34 Ibid, p. 239. 
rationality at work in the search for truth, is unavoidably conditional upon placing nonevidential, merely practical trust in the cornerstones.

\section{Closure Failure Again}

In "On Epistemic Alchemy," 35 Aidan McGlynn focuses on a different problem for welfare epistemology: closure failure. With regard to hand possession and the envatment specter, welfare epistemology allows for the following possibility:

$$
\text { CF1 } \quad \mathrm{J}_{\mathrm{E}}(\text { Hands }) \& \mathrm{~J}_{\mathrm{E}}(\text { Hands } \rightarrow \sim \mathrm{BIV}) \& \sim \mathrm{J}_{\mathrm{E}}(\sim \mathrm{BIV}) .
$$

McGlynn argues that, if we accept the possibility of CF1, we incur an unacceptable cost.

Consider the logical rule of addition as a specific instance of entailment: $p \rightarrow(p \vee q)$.

Replacing $p$ with Hands and $q$ with $\sim$ BIV, we get:

$$
\text { Hands } \rightarrow \text { (Hands } \vee \sim \text { BIV). }
$$

This is equivalent to:

$$
\text { Hands } \rightarrow \sim(\sim \text { Hands \& BIV }) .
$$

Suppose you recognize this equivalence. Now, $\sim(\sim$ Hands \& BIV), in effect, says: it's not the case that I am a handless BIV. That's a cornerstone: the very kind of proposition for which, according to Wright, we don't have $\mathrm{J}_{\mathrm{E}}$. So, on Wright's welfare epistemology, the following is possible:

\section{CF2 $\mathrm{J}_{\mathrm{E}}$ (Hands) \& $\mathrm{J}_{\mathrm{E}}[$ Hands $\rightarrow \sim(\sim$ Hands $\&$ BIV $)] \& \sim \mathrm{J}_{\mathrm{E}}[\sim(\sim$ Hands \& BIV $)]$.} So, if welfare epistemology is correct, $\mathrm{J}_{\mathrm{E}}$ is not closed under known entailment even if the entailment in question is as obvious as ' $p \rightarrow(p \vee \sim q)$ ' and the equivalence of $(p \vee \sim q)$ and $\sim(\sim p \& q)^{\prime}$. McGlynn considers this an unacceptable outcome. ${ }^{36}$

The line of reasoning McGlynn employs is meant to reveal that the pain of living with $\mathrm{J}_{\mathrm{E}}$ closure failure significantly rises once we realize that $\mathrm{J}_{\mathrm{E}}$ fails to be closed even if the known entailment is the rule of addition. For two reasons, I'm not convinced this line of reasoning succeeds. First, is CF2 really more offensive than CF1? It seems to me it isn't. If the pain of closure failure is indeed capable of degrees, then the level of pain should go up in proportion with the obviousness of the entailment in question. But when we compare the two entailments at work in CF1 and CF2, namely

35 Ibid, pp. 173-189.

${ }^{36}$ For an analogous line of reasoning, applied to knowledge closure, see Hawthorne 2004, pp. 39-41. 


\section{E1 Hands $\rightarrow \sim$ BIV}

and

E2 Hands $\rightarrow \sim(\sim$ Hands \& BIV $)$,

E1 seems more obvious than E2. So I'm inclined to say that CF1 is more painful than CF2. Second, it should be seen that, on Wright's welfare epistemology, while we have closure failure for $\mathrm{J}_{\mathrm{E}}$, we get, as pointed out above, a kind of closure:

$\left\{\mathrm{J}_{\mathrm{E}}(\right.$ Hands $) \& \mathrm{~J}_{\mathrm{E}}[$ Hands $\rightarrow \sim(\sim$ Hands \& BIV $\left.)]\right\} \rightarrow \mathrm{J}_{\mathrm{P}}[\sim(\sim$ Hands $\&$ BIV $)]$.

This mitigates the pain of closure failure to a not insignificant degree.

\section{Welfare, Dogmatism, and Non-Dogmatic Evidential Antiscepticism}

I conclude by briefly reviewing the three non-sceptical options besides outright closure denial. Each of them is inflicted with a kind of alchemy. According to welfare epistemology, $\mathrm{J}_{\mathrm{E}}$ for quotidian propositions cannot come from $\mathrm{J}_{\mathrm{E}}$ for cornerstones. Rather, it ultimately flows from $\mathrm{J}$ for cornerstones. This view involves the problematic assertion that we can get evidential juice from of a non-evidential fruit. Dogmatism denies that $\mathrm{J}_{\mathrm{E}}$ for quotidian propositions depends on justification for cornerstones. The view says that hand experiences give you, all by themselves, $\mathrm{J}_{\mathrm{E}}$ for believing you're not a BIV. Likewise, the view says that the perceptual experiences of appearing to see an oasis gives you, by itself, $\mathrm{J}_{\mathrm{E}}$ for believing you are not hallucinating an oasis. Particularly the latter claim is baffling. Finally, non-dogmatic evidential anti-scepticism agrees with welfare epistemology that $\mathrm{J}_{\mathrm{E}}$ for quotidian propositions depends on justification for cornerstones. But, unlike welfare epistemology, that view holds that we actually possess $\mathrm{J}_{\mathrm{E}}$ for cornerstones. We have $\mathrm{J}_{\mathrm{E}}$ for them because, when a particular experience says sceptical hypothesis $H$ is false, then, provided that experience is embedded in an evidential system that certifies its own reliability, we have $\mathrm{J}_{\mathrm{E}}$ for believing that that experience is not misleading, and therefore have $\mathrm{J}_{\mathrm{E}}$ for $\sim H$. Of course, that an evidential system can legitimately vouch for its own reliability, thereby supplying $\mathrm{J}_{\mathrm{E}}$ for believing that the system is not misleading, is a highly controversial idea. None of the three views, then, can leave their advocates entirely comfortable. 
References

Cohen, Stewart. 2002. "Basic Knowledge and the Problem of Easy Knowledge." Philosophy and Phenomenological Research 65: 309-329.

Comesana, Juan. 2013. “There is no Immediate Justification” and "Reply to Pryor.” In: Steup, Turri, Sosa 2013, pp. 222-35 and 239-243.

Davies, Martin. 2004. "Epistemic Entitlement, Warrant Transmission and Easy

Knowledge.”. Aristotelian Society, Supplementary Vol. 78: 213-45.

DeRose, Keith. 1995. "Solving the Skeptical Problem.” Philosophical Review 104: 1-52.

Dretske, Fred. 2005. “The Case Against Closure.” In: Steup, Turri, and Sosa 2013: 27-40.

Hawthorne, John. 2004. Knowledge and Lotteries. Oxford: Oxford University Press.

Hawthorne, John. 2005. “The Case for Closure.” In: Steup, Turri, and Sosa 2013: 40-56.

Huemer, Michael. 2001. Skepticism and the Veil of Perception. Lanham (ML): rowman and Littlefield.

Pryor, James. 2000. "The Skeptic and the Dogmatist." Nous 34: 517-549.

Pryor, James. 2004. “What's Wrong with Moore’s Argument?” Philosophical Issues 14 (1):349378.

Pryor, James. 2013. “There is Immediate Justification” and "Reply to Comesaña." In: Steup, Turri, Sosa (eds.) 2013, pp. 202-22 and 235-239.

Steup, Matthias. 2004. Internalist Reliabilism. Philosophical Issues 14: 403-425.

Steup, Matthias. 2008. “Evidentialist Anti-Skepticism,” in Trent Dougherty (ed.), Evidentialism and Its Discontents: 105-122. New York: Oxford University Press.

Steup, Matthias. 2013. “Is Epistemic Circularity Bad?” Res Philosophica 90 (2013): 215-235.

Steup, Matthias, John Turri, and Ernest Sosa (eds). 2013b. Contemporary Debates in Epistemology ( $2^{\text {nd }}$ edition). Oxford: Wiley Blackwell.

Tucker, Chris. 2014. Seemings and Justification. New Essays on Dogmatism and Phenomenal Conservatism. Oxford: Oxford University Press.

Wright, Crispin. 2004. "On epistemic Entitlement: Warrant for Nothing (and Foundations for Free?)" Aristotelian Society, Supplementary Vol. 78: 167-212. 